Check for updates

University of Bristol Population Health Sciences and UK National Screening Programmes, Bristol, UK

2 London, UK

Cite this as: BMJ 2022;376:0445 http://dx.doi.org/10.1136/bmj.0445 Published: 23 February 2022

\title{
Self-testing for asymptomatic non-contacts using rapid antigen tests-is this leading to a cost effective reduction in infection transmission?
}

Angela E Raffle, ${ }^{1}$ Mike Gill ${ }^{2}$

Rapid tests that give near instant results, without the need of a laboratory, offer much promise. But, to ensure value for public money we need rigorous evaluation of test performance in real life settings, and empirical assessment of the consequences-intended and unintended-when mass testing and intervention are applied within a population. ${ }^{1}$ Evolution in technology, in the condition being tested for, and other changes in context mean that regular reappraisal of policy is important. Yet commercial and political incentives to promote tests irrespective of evidence can be irresistible. The popularity of testing for asymptomatic people among the public has seldom borne much relationship to actual utility of the test. ${ }^{2}$

In 1975, Sackett and Holland-founding figures in the development of evidence based and high quality health screening-remarked that, "There remains a basic ideological dispute between the advocates of screening ('evangelists') and the advocates of the scientific method ('snails')." ${ }^{3}$ A research paper in The BMJ this week adopts the scientific method and applies what little empirical real world evidence we have concerning test performance of the SARS-CoV-2 lateral flow antigen test widely used in the UK, to two models influential in underpinning policy for mass rapid testing. ${ }^{4}$ The research concludes that the models overestimated the capacity of the Innova test to detect infectiousness, especially in asymptomatic people. Importantly, the poorest apparent test performance comes from studies that genuinely recruited people without symptoms. ${ }^{5}$

Counterarguments that asymptomatic people with negative lateral flow and positive polymerase chain reaction test results must all have been post-infection and therefore not infectious, lack credibility. The clear implication is that any positive impact from the detection of asymptomatic people may be outweighed by the effects of infectious people being falsely reassured and therefore mixing with others, perhaps even ignoring their symptoms. ${ }^{6}$

When rapid antigen tests were introduced, we were promised they would "identify those who are likely to spread the disease, and when used systematically in mass testing could reduce transmissions by $90 \%$." 7 Yet despite the UK spending more than $€ 7 \mathrm{bn}$ on lateral flow devices since mid-2020, the lack of hard evidence on this promised impact is striking. ${ }^{8}$

Observational studies attempting to assess the impact on transmission as a result of testing asymptomatic non-contacts have struggled to show an effect. None seem to have examined the costs of the programmes. Detailed analysis of data from a major pilot of mass testing that reached up to $16 \%$ of Liverpool City's population used hospital admissions as the outcome of interest and found a $32 \%$ lower admission rate compared with synthetic controls-and after adjustment for variations in covid-19 restrictions. ${ }^{9}$ Yet the admission trend in Liverpool at the time was already downwards, and numerous intervening variables were at play. Whether the testing of a self-selecting $16 \%$ or less of the population can be credited with this $32 \%$ difference is unknown. In a programme of mandatory direct observation of rapid antigen testing of participants in a sports programme in the USA, two outbreaks of covid-19 resulted from students mixing with others on the same day as a negative test result and subsequently being confirmed as infectious. ${ }^{10}$

International comparisons are complex and influenced by many factors, but Japan, which has actively limited widespread self-testing, has a covid-19 death rate an order of magnitude less than that of the UK, Germany, where testing of asymptomatic people has been a feature, and the USA. ${ }^{11}$ The World Health Organisation cautions against mass asymptomatic testing because of high costs, lack of evidence on the impact, and risk of diverting resources from more important activities. ${ }^{12}$

Both the Innova (Biotime) test and the more recently issued Flowflex test are being used outside of their original manufacturers' recommendations. ${ }^{13} 14$ Neither test has been thoroughly evaluated for self-testing or for use in asymptomatic people. No reference standard or cut-off measure for infectiousness exists, unlike the familiar lateral flow test target condition of pregnancy, which is a discrete variable.

When the high cost to low benefit ratio is pointed out, we are told that more screening is needed, or that the tests are "transformational" and "a part of daily life." ${ }^{15}{ }^{16}$ Everyday use of tests may indeed be transformational for those with a stake in the testing industry, but the financial burden is borne by taxpayers. If testing had been better targeted and based on solid evaluation from the start, then the current move to self-funding of tests would probably not be happening.

Unsurprisingly, testing is therefore chaotic and wasteful. Social media reports of discrepant results between lateral flow and polymerase chain reaction tests abound. Messages to the public about the reliability of these tests, and about whether, when, and how to self-test are mixed and ever changing. A recent You Gov poll revealed that most people have not changed their behaviour in response to the 
omicron variant, and most are not self-testing before mixing or in response to being a possible contact. ${ }^{17}$ Surely it is time to start afresh. Publication of this new paper should prompt the Medicines and Healthcare Products Regulatory Agency to reassess its authorisations of rapid antigen tests in asymptomatic people. The public deserves to have better evaluations, ensuring good test performance in real life settings, and a policy that specifies effective and efficient test use for carefully targeted purposes.

Competing interests: none declared

Provenance and peer review: commissioned, not externally peer reviewed

1 Public Health England. (2015) Criteria for appraising the viability, appropriateness and effectiveness of a screening programme. https://www.gov.uk/government/publications/evidence-review-criterianational-screening-programmes/criteria-for-appraising-the-viability-effectiveness-and-appropriateness-of-a-screening-programme

2 Schwartz LM, Woloshin S, Fowler FJ, JrWelch HG. Enthusiasm for cancer screening in the United States. JAMA 2004;291:71-8. doi: 10.1001/jama.291.1.71 pmid: 14709578

3 Sackett DL, Holland WW. Controversy in the detection of disease. Lancet 1975;2:357-9. doi: 10.1016/S0140-6736(75)92790-7 pmid: 51154

4 Deeks JJ, Singanayagam A, Houston H, etal. SARS-CoV-2 antigen lateral flow tests for detecting infectious people: linked data analysis. BMJ2022;376:e66871. doi: 10.1136/bmj-2021-066871.

5 Dinnes J, et al. Rapid, point-of-care antigen and molecular-based tests for diagnosis of SARS-CoV-2 infection https://www.cochranelibrary.com/cdsr/doi/10.1002/14651858.CD013705.pub2/full

6 Raffle AE, Taylor-Phillips S, Sitch A. Mapping the outcomes of covid-19 testing reveals the best opportunities for system improvement. BMJ Opinion April 9, 2021

https://blogs.bmj.com/bmj/2021/04/09/mapping-the-outcomes-of-covid-19-testing-programmesreveals-the-best-opportunities-for-improvement/

7 Oxford University News and Events. (Nov 2020) Oxford University and PHE confirm lateral flow tests show high specificity and are effective at identifying most individuals who are infectious. https:/www.ox.ac.uk/news/2020-11-11-oxford-university-and-phe-confirm-lateral-flow-testsshow-high-specificity-and-are

8 Daily Mail https://www.dailymail.co.uk/news/article-10365883/The-lateral-flow-tycoons-tinyUK-firm-20m-profit-thanks-Covid-role.html

9 University of Liverpool. (Dec 2021) Covid-SMART Asymptomatic Testing Pilot in Liverpool City Region: Quantitative Evaluation. https://www.liverpool.ac.uk/media/livacuk/coronavirus/Liverpool_City_Region_Covid_SMART_Evaluation.pdf

10 Moreno GK, Braun KM, Pray IW, etal. Severe Acute Respiratory Syndrome Coronavirus 2 Transmission in Intercollegiate Athletics Not Fully Mitigated With Daily Antigen Testing. Clin Infect Dis 2021;73(Suppl 1):S45-53. doi: 10.1093/cid/ciab343. pmid: 33977295

11 Pettengill M. (2021) Real world performance of COVID-19 Rapid Antigen Tests. American Society of Microbiology. https://asm.org/Articles/2021/December/Real-World-Performance-of-COVID-19Rapid-Antigen-T?S=03\#.YdStA3UIFXY [accessed 9 Jan 2022]

12 World Health Organisation (2021) Antigen-detection in the diagnosis of SARS-CoV-2 infection. Interim Guidance 6 October 2021

13 https://cdn.website-editor.net/6f54caea7c6f4adfba8399428f3c0b0c/files/uploaded/InnovaSARS-Cov-2-Antigen-test-IFU.pdf

14 https://www.aconlabs.com/wp-content/uploads/2020/11/2200029901-Labs-CE-SARS-CoV-2Antigen-Rapid-Test-Sell-Sheet.pdf

15 Larremore $\mathrm{DB}$, Wilder $\mathrm{B}$, Lester $\mathrm{E}$, etal. Test sensitivity is secondary to frequency and turnaround time for COVID-19 screening. Sci Adv 2021;7:eabd5393. doi: 10.1126/sciadv.abd5393. pmid: 33219112

16 Devlin H. (2022) The rise of lateral flow tests: are these 'heroes' of the pandemic here to stay? The Guardian. 7 January 2022 https://www.theguardian.com/world/2022/jan/07/the-rise-of-lateral-flow-tests-are-these-heroes-of-the-pandemic-here-to-stay

17 Wright O. (2021) Poll reveals public wants to party on despite rapid spread of Omicron. https://www.thetimes.co.uk/article/poll-reveals-public-wants-to-party-on-despite-rapid-spreadof-omicron-mw997k8hs 